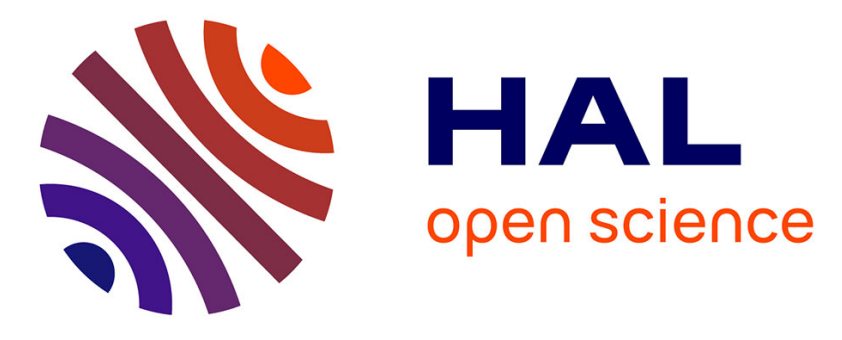

\title{
Physiological characterisation of the efflux pump system of antibiotic-susceptible and multidrug-resistant
}

\author{
A. Martins, G. Spengler, M. Martins, L. Rodrigues, M. Viveiros, A. \\ Davin-Regli, Jérome Chevalier, I. Couto, J.M. Pagès, L. Amaral
}

\section{> To cite this version:}

A. Martins, G. Spengler, M. Martins, L. Rodrigues, M. Viveiros, et al.. Physiological characterisation of the efflux pump system of antibiotic-susceptible and multidrug-resistant. International Journal of Antimicrobial Agents, 2010, 36 (4), pp.313. 10.1016/j.ijantimicag.2010.06.036 . hal-00616235

\section{HAL Id: hal-00616235 \\ https://hal.science/hal-00616235}

Submitted on 20 Aug 2011

HAL is a multi-disciplinary open access archive for the deposit and dissemination of scientific research documents, whether they are published or not. The documents may come from teaching and research institutions in France or abroad, or from public or private research centers.
L'archive ouverte pluridisciplinaire HAL, est destinée au dépôt et à la diffusion de documents scientifiques de niveau recherche, publiés ou non, émanant des établissements d'enseignement et de recherche français ou étrangers, des laboratoires publics ou privés. 


\section{Accepted Manuscript}

Title: Physiological characterisation of the efflux pump system of antibiotic-susceptible and multidrug-resistant Enterobacter aerogenes

Authors: A. Martins, G. Spengler, M. Martins, L. Rodrigues, M. Viveiros, A. Davin-Regli, J. Chevalier, I. Couto, J.M.

Pagès, L. Amaral

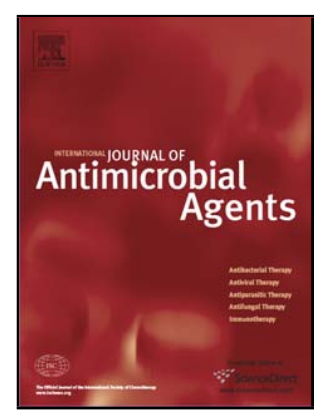

PII:

DOI:

Reference:

S0924-8579(10)00294-3

ANTAGE 3372

To appear in: International Journal of Antimicrobial Agents

Received date: $\quad 15-4-2010$

Revised date: $\quad 13-6-2010$

Accepted date: $\quad 14-6-2010$

Please cite this article as: Martins A, Spengler G, Martins M, Rodrigues L, Viveiros M, Davin-Regli A, Chevalier J, Couto I, Pagès JM, Amaral L, Physiological characterisation of the efflux pump system of antibiotic-susceptible and multidrugresistant Enterobacter aerogenes, International Journal of Antimicrobial Agents (2010), doi:10.1016/j.ijantimicag.2010.06.036

This is a PDF file of an unedited manuscript that has been accepted for publication. As a service to our customers we are providing this early version of the manuscript. The manuscript will undergo copyediting, typesetting, and review of the resulting proof before it is published in its final form. Please note that during the production process errors may be discovered which could affect the content, and all legal disclaimers that apply to the journal pertain. 


\section{Physiological characterisation of the efflux pump system of antibiotic-susceptible and multidrug-resistant Enterobacter aerogenes}

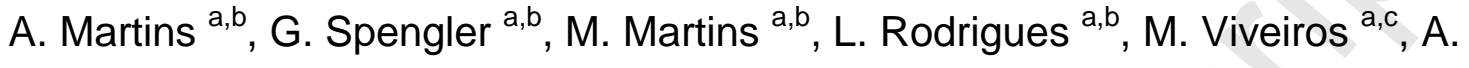
Davin-Regli $^{c, d}$, J. Chevalier $^{c}$, I. Couto ${ }^{a, e}$, J.M. Pagès ${ }^{c, d}$, L. Amaral ${ }^{a, b, c, *}$

a Unit of Mycobacteriology, Instituto de Higiene e Medicina Tropical,

Universidade Nova de Lisboa, Rua da Junqueira 96, 1349-008 Lisboa, Portugal

b UPMM, Instituto de Higiene e Medicina Tropical, Universidade Nova de Lisboa,

Rua da Junqueira 96, 1349-008 Lisboa, Portugal

${ }^{c}$ COST Action BM0701 (ATENS) of the European Commission/ESF, Brussels,

Belgium

d UMR-MD-1, IFR88, Facultés de Médecine et de Pharmacie, Université de la

Méditerranée, Marseille, France

e Centro de Recursos Microbiológicos (CREM), Faculdade de Ciências e

Tecnologia, Universidade Nova de Lisboa, 2829-516 Caparica, Portugal

ARTICLE INFO

Article history:

Received 15 April 2010

Accepted 14 June 2010 
Keywords:

Enterobacter aerogenes

Multidrug resistance

Efflux pump overexpression

Automated ethidium bromide method

Modulation by $\mathrm{pH}$

Modulation by glucose

* Corresponding author. Present address: Unit of Mycobacteriology/UPMM, Institute of Hygiene and Tropical Medicine, Universidade Nova de Lisboa, 1349-

008 Lisbon, Portugal. Tel.: +351 21365 2653; fax: +351213632105.

E-mail address: lamaral@ihmt.unl.pt (L. Amaral). 


\section{ABSTRACT}

Enterobacter aerogenes predominates among Enterobacteriaceae species that are increasingly reported as producers of extended-spectrum $\beta$-lactamases.

Although this mechanism of resistance to $\beta$-lactams is important, other mechanisms bestowing a multidrug-resistant (MDR) phenotype in this species are now well documented. Among these mechanisms is the overexpression of efflux pumps that extrude structurally unrelated antibiotics prior to their reaching their targets. Interestingly, although knowledge of the genetic background behind efflux pumps is rapidly advancing, few studies assess the physiological nature of the overall efflux pump system of this, or for that matter any other, bacterium. The study reported here evaluates physiologically the efflux pump system of an E. aerogenes ATCC reference as well as two strains whose MDR phenotypes are mediated by overexpressed efflux pumps. The activities of the efflux pumps in these strains are modulated by $\mathrm{pH}$ and glucose, although the effects of the latter are essentially restricted to $\mathrm{pH} 8$, suggesting the presence of two general efflux pump systems, i.e. proton-motive force-dependent and $A B C$ transporter types, respectively. 


\section{Introduction}

The advent of multidrug resistance in Gram-negative bacteria has increased the range of infections owing to the problematic nature of therapy. Consequently, infections by Enterobacter aerogenes that were once less frequent are now becoming increasingly more frequent in the hospital environment [1]. As an example, two clones of ceftazidime-resistant $E$. aerogenes have been spreading throughout Belgian hospitals to the point that they have become a serious healthcare issue both in hospitals and in the community [2]. Moreover, strains of E. aerogenes now account for $>50 \%$ of all Gram-negative organisms that produce extended-spectrum $\beta$-lactamases (ESBLs) and, inasmuch as ESBLs are the major cause of treatment failure, the opportunity for the development of multidrug-resistant (MDR) phenotypes has resulted [3]. Among the mechanisms that contribute to a MDR phenotype in E. aerogenes is overexpression of genes that regulate and code for efflux pumps which extrude unrelated antibiotics before they reach their intended targets [4]. Interestingly, whilst the appearance of multidrug resistance in this species has been essentially made possible by the production and release of type $C \beta$-lactamases, the existence of an overexpressed efflux pump further contributes to the progressive evolution of multidrug resistance [4-6].

The MDR phenotype of E. aerogenes coupled with its ESBL-producing capacity has resulted in increased emergence of this pathogen in hospital units [7-9] and 
in the description by the media as 'killer bugs' or 'superbugs'. Indeed, the infections they cause result in a high cost in terms of morbidity, treatment failures and subsequent mortality [2]. Although at the time of this writing no agents are available for inhibition of type $C \beta$-lactamases, a variety of agents have been identified as having the potential to inhibit overexpressed efflux pumps of Gramnegative bacteria [10]. However, although some of these inhibitors of efflux pumps affect the function of the pump itself [efflux pump inhibitors (EPIs)] $[11,12]$, there is now evidence that some EPIs may have an effect on regulatory genes involved in the control of efflux expression and genes that code for transporters $[13,14]$. Because of this, assessment of EPIs must also include their potential genetic actions. Nevertheless, although the genetic basis for an overexpressed efflux pump is essential, the actual function of an efflux pump need not be compatible with its level of genetic expression and regulation [15]. As an example, in Escherichia coli strains whereas transcription of the acrEF gene is 80 -fold greater in a tetracycline-resistant strain than that of its parental tetracycline-susceptible strain, its level of resistance is equal to that of the tetracycline-resistant strain whose $a c r A B$ is transcribed only 6 -fold above that of its parent [15].

With the exception of some early demonstrations of efflux pumps as well as a recent report [16], assessment of the function of specific efflux pumps is essentially absent from the literature. Understanding that resistance-nodulationcell division (RND) tripartite efflux pumps derive their energy for function from the 
membrane $\Delta p$ (potential gradient, $\Delta p=\Delta \varphi+R T \log \Delta p H$, where $\Delta \varphi$ is the difference in electrochemical gradient across the membrane, RT is the amount of ATP harnessed at $37^{\circ} \mathrm{C}$ and $\Delta \mathrm{pH}$ is the difference in $\mathrm{pH}$ across the membrane) (proton-motive force across inner membrane) suggests that the efficacy of these pumps would be best at low $\mathrm{pH}$ and less so at $\mathrm{pH}>7$ given the paucity of protons at the latter $\mathrm{pH}$. At $\mathrm{pH}>7$ one would suppose that ATP-binding cassette (ABC)type transporters would derive their energy from the hydrolysis of ATP, inasmuch as such hydrolysis would be favoured by the $F_{0}-F_{1}$ energy system of the cell [17]. Moreover, because the dissociation constant $\left(K_{d}\right)$ for substrates bound by the AcrB transporter is low at high $\mathrm{pH}$ and high at low $\mathrm{pH}$ [18], the dissociation of a substrate such as ethidium bromide (EB) from the AcrB transporter could be sufficiently slow at physiological $\mathrm{pH} 7$ to render the $\mathrm{Acr} A B$ efflux pump somewhat limited if the organism is challenged with a noxious substrate that it must extrude for its survival [19]. Given these considerations, the described study here has assessed the role of $\mathrm{pH}$ in the activity of the efflux pump system of the intrinsically susceptible $E$. aerogenes ATCC reference strain as well as two MDR phenotypic strains whose resistance is due to an overexpressed efflux pump system. 


\section{Materials and methods}

\subsection{Materials}

Mueller-Hinton $(\mathrm{MH})$ in powder form was used for the preparation of $\mathrm{MH}$ broth and $\mathrm{MH}$ agar. Antibiotics in powder form were purchased from Difco Laboratories (Detroit, MI). EB, carbonyl cyanide m-chlorophenylhydrazone (CCCP) and PheArg- $\beta$-naphthylamide $(P A \beta N)$ were purchased from Sigma-Aldrich Química SA (Madrid, Spain).

\subsection{Bacteria}

Antibiotic-susceptible E. aerogenes ATCC 13048 and MDR E. aerogenes EA27 and CM64 strains have been previously fully characterised $[6,20,21]$. The MDR strains are resistant to norfloxacin, chloramphenicol, tetracycline and other antibiotics and overexpress the AcrAB-TolC efflux pump [6,20,21].

\subsection{Methods}

\subsubsection{Minimum inhibitory concentrations (MICs)}

The MIC of antibiotics, CCCP and PA $\beta N$ against the strains employed in this study were determined in $\mathrm{MH}$ medium adjusted to $\mathrm{pH} 5,7$ and 8 by the microbroth dilution method according to Clinical and Laboratory Standards Institute guidelines [22]. 
2.3.2. Assessment of putative efflux of ethidium bromide by the ethidium bromide agar method

Assessment of efflux by the EB agar method has been previously described in detail $[23,24]$. Briefly, plates of $\mathrm{MH}$ agar of $\mathrm{pH} 5,7$ and 8 containing increasing concentrations of EB were swabbed with each bacterial strain as spokes of a wheel (cartwheel manner) and the plates were incubated for $18 \mathrm{~h}$ at $37^{\circ} \mathrm{C}$, examined under ultraviolet light and photographed using a GEL DOC XR instrument (Bio-Rad Laboratories, Hercules, CA). The minimum concentration of EB that produces fluorescence indicates that the amount of EB that the cell can extrude has been exceeded and hence EB accumulates within the cell.

\subsubsection{Assessment of efflux pump activity}

Assessment of efflux pump activity was conducted by the automated EB method as described previously [25]. This method affords a real-time estimation of accumulation of EB and its efflux. Briefly, strains were cultured in $\mathrm{MH}$ medium until they reached an optical density at $600 \mathrm{~nm}\left(\mathrm{OD}_{600}\right)$ of 0.6 and centrifuged at $13000 \mathrm{rpm}$ for $3 \mathrm{~min}$. The pellets were re-suspended in saline buffer, the $\mathrm{OD}_{600}$ adjusted to 0.6 and $1 \mathrm{~mL}$ aliquots were transferred to microtubes. The microtubes were centrifuged and the pellets were re-suspended in saline buffer at $\mathrm{pH} 5,7$ or 8 . Aliquots of $0.045 \mathrm{~mL}$ were transferred to microtubes of $0.1 \mathrm{~mL}$ and then $0.045 \mathrm{~mL}$ of $\mathrm{EB}$ in glucose-free saline of $\mathrm{pH} 5,7$ and 8 was added to 
the respective tubes of the same $\mathrm{pH}$. Because metabolic energy is required for efflux of EB, the absence of glucose ensures sufficient accumulation of the agent. The final concentration of EB for all experiments was $1.0 \mathrm{mg} / \mathrm{L}$. As concentrations of EB much greater than $1 \mathrm{mg} / \mathrm{L}$ exceed the ability of the cell to extrude the agent, the level of intracellular agent rapidly increases and results in its intercalation between the nucleic bases of DNA. EB when bound to DNA is no longer available for extrusion [26]. The tubes were rapidly transferred to a Corbett 3000 thermocycler (Qiagen, Doncaster, Australia) programmed with cycles of $1 \mathrm{~min}$ at a constant temperature of $37^{\circ} \mathrm{C}$. The total average time from addition of the EB-saline to as many as 12 individual tubes to the transfer of the tubes to the instrument and re-starting the instrument did not exceed $60 \mathrm{~s}$. Accumulation of EB in each tube was followed on a real-time basis by assessment of fluorescence emitted. Excitation and emission wavelengths were $535 \mathrm{~nm}$ and $585 \mathrm{~nm}$, respectively. Whereas the medium containing $1.0 \mathrm{mg} / \mathrm{L}$ of EB does not appreciably fluoresce, as the concentration of EB builds up in the periplasm of the Gram-negative bacterium, fluorescence is readily detected by the instrument [23]. Accumulation of EB at various $\mathrm{pH}$ levels was followed for up to $25 \mathrm{~min}$.

Assessment of efflux of EB at $\mathrm{pH} 5,7$ and 8 was conducted as follows. Accumulation of $\mathrm{EB}$ at $\mathrm{pH} 5,7$ and 8 as described above was first conducted for up to $25 \mathrm{~min}$, after which time the instrument was stopped and $0.010 \mathrm{~mL}$ of saline at $\mathrm{pH} 5,7$ and 8 either lacking or containing glucose to yield a concentration of 
$0.4 \%$ was added to the respective tubes. The tubes were then transferred to the instrument and the instrument was re-started. The total amount of time for this addition did not exceed 2.5 min. Fluorescence was followed for a minimum period of $10 \mathrm{~min}$.

The effects of varying concentrations of CCCP and PA $\beta N$ on efflux of EB was carried out as follows. Accumulation of EB in glucose-free saline of $\mathrm{pH} 5,7$ and 8 was conducted as described and when the plateau of accumulation was reached the instrument was stopped and $0.045 \mathrm{~mL}$ of glucose-saline of $\mathrm{pH} 5,7$ and 8 containing varying containing $\mathrm{CCCP}$ and $\mathrm{PA} \beta \mathrm{N}$ was added to the salinecontaining tubes at the respective $\mathrm{pH}$. The tubes were placed into the instrument, the instrument was re-started and fluorescence was followed for up to $15 \mathrm{~min}$. The total time for these additions did not exceed $2.5 \mathrm{~min}$. For some experiments, addition of CCCP at varying concentrations was in matched-pH glucose-free medium. This component of the experiment afforded an additional control that would define any role of metabolic energy in conjunction with any effect produced by given concentrations of CCCP on efflux of EB and modulation of efflux at a given $\mathrm{pH}$. The concentrations of CCCP and PA $\beta N$ were $<0.25 \times \mathrm{MIC}$ and had no effect on the viability of the $E$. aerogenes strains employed in this study. 


\section{Results}

The MICs of various antibiotics against the $E$. aerogenes strains used in this study are presented in Table 1. As noted in the table, the CM64 and EA27 strains that overexpress the AcrAB efflux pump exhibit a MDR phenotype. Evaluation of the effect of agents for inhibitory activity against efflux requires that the agent be used at a concentration that has no significant effect on the viability and growth rate of the bacterium [29]. Consequently, the MICs of EB, CCCP and PA $\beta N$ against each of the $E$. aerogenes strains were also determined in $\mathrm{MH}$ broth at $\mathrm{pH}$ 5 and 8 , thus allowing the selection of concentrations that had no effect on the viability of the strains employed in this study (data not shown).

The effect of $\mathrm{pH}$ on retention of EB by the E. aerogenes strains is illustrated in Fig. 1. Whereas at $\mathrm{pH} 8$ fluorescence is detected for all of the strains at $0.5 \mathrm{mg} / \mathrm{L}$ $\mathrm{EB}$, at $\mathrm{pH} 5$ the $\mathrm{CM} 64$ and EA27 strains do not fluoresce even with a concentration as high as $2.5 \mathrm{mg} / \mathrm{L}$ EB. Unlike these latter MDR strains, the ATCC 13048 strain begins to fluoresces with $0.2 \mathrm{mg} / \mathrm{L} \mathrm{EB}$ at $\mathrm{pH} 5$ (data not shown). These results collectively suggest that: (i) the viability of the organism is not affected by concentrations as high as $600 \mathrm{mg} / \mathrm{L} \mathrm{EB}$; (ii) permeability of the strains to $\mathrm{EB}$ at $\mathrm{pH} 8$ is sufficient with a concentration of $\mathrm{EB}$ as low as $0.5 \mathrm{mg} / \mathrm{L}$; (iii) the strains are able to extrude EB given the difference observed between ATCC and resistant strains; and (iv) the MDR strains EA27 and CM64 have an 
overexpressed efflux pump system that is readily evident at $\mathrm{pH} 5$ compared with that present in the ATCC 13048 strain $[4,5,27]$.

The effect of $\mathrm{pH}$ and glucose on the accumulation of EB by the strains was evaluated by the automated EB method [19]. As shown in Fig. 2, accumulation of EB by the ATCC 13048 strain is not affected by pH unless glucose is absent from the medium, and only at $\mathrm{pH} 8$. Similar results were obtained with the MDR strains EA27 and CM64 (data not shown). These results suggest that at $\mathrm{pH} 8$ extrusion of EB is markedly affected by the absence of glucose, as would be expected if the efflux pump system at this $\mathrm{pH}$ was dependent on the membrane energy conferred by glucose metabolism (hydrolysis of ATP). Because no accumulation per unit period of time takes place at $\mathrm{pH} 5$ where the $\Delta \mathrm{pH}$ is strong [19], intracellular concentration of EB is dependent only on the availability of protons and is independent of metabolic energy (glucose). The accumulation assays without glucose at $\mathrm{pH} 5$ and 8 were repeated and after 25 min the instrument was put into its pause mode and $\mathrm{pH}$-matched saline containing glucose to yield a final concentration of $0.4 \%$ was added and the instrument re-started. As shown in Fig. 3, addition of glucose at pH 8 to the ATTC 13048- and CM64-containing tubes immediately causes a drop in fluorescence from 10 to 25 fluorescence units compared with the control without glucose. This drop in fluorescence is maintained for the duration of the assay. At pH 5, glucose has no effect. These results demonstrate that at $\mathrm{pH} 8$ efflux is dependent upon a source of metabolic energy (glucose). 
To determine that the degree of fluorescence reflective of accumulation of EB is indeed due to an efflux pump system, the EB accumulation assay was repeated with glucose-free saline at $\mathrm{pH} 5$ and 8 for each of the $E$. aerogenes strains. After the instrument was put into pause mode, varying concentrations of CCCP, an uncoupler of membrane energy, in glucose-containing saline of $\mathrm{pH} 5$ and 8 were added, the instrument was re-started and the amount of relative fluorescence was followed for an additional $10 \mathrm{~min}$. Addition of $\mathrm{pH}$-matched saline with and without glucose served as controls. The data presented in Fig. 4 are for addition of $5 \mathrm{mg} / \mathrm{L} \mathrm{CCCP.} \mathrm{As} \mathrm{is} \mathrm{evident} \mathrm{from} \mathrm{Fig.} 4$, addition of CCCP at $\mathrm{pH} 5$ causes an increase in the amount of fluorescence due to EB retained by the ATCC 13048 strain and a considerably lower increase for the two MDR strains EA27 and CM64. At pH 8, addition of CCCP markedly increases accumulation of EB in the ATCC 13048 and EA27 strains to the same level but does not affect the accumulation of EB by the $\mathrm{CM} 64$ strain, suggesting that at $\mathrm{pH} 8$ the extrusion of $E B$ is taking place by an $A B C$ transporter that receives its energy directly from the hydrolysis of ATP [19].

The smaller effect of CCCP on the accumulation of EB at $\mathrm{pH} 5$ noted for the ATCC and EA27 strains is interpreted to be due to the large concentration of surface protons $[19,30]$ that exceed the binding capacity of CCCP. At pH 8 , the proton concentration is rapidly bound such that the antiport proton-dependent efflux pump system of the ATCC 13048 and EA27 strains is denied the required 
energy for its action. At pH 8 any contribution made by the presence of metabolic energy is masked by the acute accumulation of EB produced by CCCP. Unlike the effects of CCCP on the ATCC 13048 and EA27 strains, addition of CCCP has no effect on the accumulation of EB by the CM64 strain.

PA $\beta N$ has been repeatedly described as an EPI $[31,32]$. However, our recent results suggest that $P A B N$ has no effect on efflux but has an effect on accumulation. The effect of PABN on intracellular concentration is not due to direct inhibition of efflux pump activity but rather to competition with EB transport $[19,24,25]$. Nevertheless, we first assessed PA $\beta N$ for any effect on efflux, and hence accumulation, of EB by each of the strains in glucose-free medium at $\mathrm{pH} 5$ and 8; after $25 \mathrm{~min}, 20 \mathrm{mg} / \mathrm{L}$ and $40 \mathrm{mg} / \mathrm{L} \mathrm{PA} \beta \mathrm{N}$ in glucose-containing medium was added. As shown in Fig. 5, addition of PA $\beta N$ in glucose-containing saline at $\mathrm{pH} 5$ and 8 has no effect on accumulation of EB by any of the $E$. aerogenes strains, even with a concentration as high as $40 \mathrm{mg} / \mathrm{L}$. The additions contained glucose to ensure that the metabolic energy required for efflux at $\mathrm{pH} 8$ was readily available.

\section{Discussion}

The two overexpressing strains studied in this work differ in terms of overexpression of efflux pumps, mutations and porin expressions [21,27]. According to Ghisalberti et al. [21], strain CM64, which became resistant 
following prolonged exposure to increasing concentrations of chloramphenicol, presents overexpression of the AcrAB-TolC efflux pump. However, strain EA27, a clinical isolate also resistant to chloramphenicol, was reported as having a deletion in the acrR gene that induces upregulation of the $a c r A B$ efflux pump operon as well as exhibiting lower expression of Omp36, the major non-specific porin of E. aerogenes [21]. In contrast to EA27, the opposite is true for the CM64 and the parental strains $[21,27]$. These differences in resistance mechanisms adopted by the two MDR strains were also visible in our work. CM64 shows resistance mechanisms dependent on $\mathrm{pH}$ and glucose availability. On the other hand, these effects are not evident for the EA27 and ATCC strains. Because the mechanisms of resistance of the CM64 strain are based on overexpression of the AcrAB efflux pump, extrusion of $E B$ is mediated by proton changes obtained directly from the transmembrane proton gradient. At $\mathrm{pH} 8$, owing to slow dissociation of the EB substrate from the AcrB transporter [18], efflux by the RND AcrAB efflux pump may be limited. It is at this $\mathrm{pH} 8$ where the need for metabolic energy (glucose) is evident, suggesting the involvement of a putative $A B C$ transporter [19].

At neutral $\mathrm{pH}$, the energy derived from glucose or other sources is used to export cytoplasmic $\mathrm{H}^{+}$to the periplasmic space where it is used by the AcrB pump for drug antiport activity. Addition of CCCP collapses the energy of proton transport to the periplasm, reducing the $\mathrm{H}^{+}$concentration within the periplasm and consequently altering $\mathrm{AcrB}$ function. At acidic $\mathrm{pH}$, the proton periplasmic 
concentration is high and CCCP cannot downregulate the activity of the AcrB pump.

$P A \beta N$ is again shown not to have any effect on EB efflux by Gram-negative bacteria $[19,23,25]$, confirming that the mechanism by which $P A \beta N$ reduces efflux-mediated resistance to a given antibiotic is due to competition between $P A \beta N$ and $E B$ [33]. The degree of competition has recently been shown to be in favour of extrusion of PA $\beta N$, resulting in a Henri-Michaelis-Menten constant $\left(\mathrm{K}_{\mathrm{M}}\right)$ of $4.21 \mathrm{mg} / \mathrm{L}$ versus $1 \mathrm{mg} / \mathrm{L}$ EB by the efflux machinery of $E$. coli [19]. Lastly, because dissociation of an AcrB substrate is very fast at low pH [18], if a true inhibitor of an efflux pump is to be designed its activity must be assessed at $\mathrm{pH} 5$ to ensure that it truly binds and inhibits the RND efflux pump of Gram-negative bacteria.

It is also interesting to mention that $P A B N$ is able to increase significantly, at neutral $\mathrm{pH}$, the intracellular accumulation of chloramphenicol in the $E$. aerogenes strains tested [28]. This increase suggests that PA $\beta N$ and chloramphenicol may use the same affinity sites in the AcrB cavity, in contrast to EB. Consequently, PA $\beta N$ may successfully compete for extrusion with chloramphenicol as previously reported and partially restore chloramphenicol susceptibility in different efflux-mediated resistant strains [19]. Alternatively, EB may use a 
parallel efflux pump during the fist step before reaching the central AcrB cavity that is open to the TolC exit canal [34].

At this moment, it is important to note that $E$. aerogenes, like $E$. coli, is a commensal bacterium of the digestive tract where it faces an acidic $\mathrm{pH}$ that consequently may provide sufficient periplasmic proton concentration to drive the proton antiport necessary for drug extrusion.

\section{Funding}

None.

\section{Competing interests}

None declared.

\section{Ethical approval}

Not required. 


\section{References}

[1] Deal EN, Micek ST, Ritchie DJ, Reichley RM, Dunne WM Jr, Kollef MH. Predictors of in-hospital mortality for bloodstream infections caused by Enterobacter species or Citrobacter freundii. Pharmacotherapy 2007;27:1919.

[2] Goossens H. Antibiotic resistance and policy in Belgium. Verh K Acad Geneeskd Belg 2000;62:439-69.

[3] Giamarellou H. Multidrug resistance in Gram-negative bacteria that produce extended-spectrum $\beta$-lactamases (ESBLs). Clin Microbiol Infect 2005;11:116.

[4] Davin-Regli A, Bolla JM, James CE, Lavigne JP, Chevalier J, Garnotel E, et al. Membrane permeability and regulation of drug 'influx and efflux' in enterobacterial pathogens. Curr Drug Targets 2008;9:750-9.

[5] Martins A, Iversen C, Rodrigues L, Spengler G, Ramos J, Kern WV, et al. An AcrAB-mediated multidrug-resistant phenotype is maintained following restoration of wild-type activities by efflux pump genes and their regulators. Int J Antimicrob Agents 2009;34:602-4.

[6] Chevalier J, Mulfinger C, Garnotel E, Nicolas P, Davin-Régli A, Pagès JM. Identification and evolution of drug efflux pump in clinical Enterobacter aerogenes strains isolated in 1995 and 2003. PLoS One 2008;3:e3203.

[7] Vogelaers D, De Bels D, Forêt F, Cran S, Gilbert E, Schoonheydt K, et al.; ANTHICUS Study Investigators. Patterns of antimicrobial therapy in severe 
nosocomial infections: empiric choices, proportion of appropriate therapy, and adaptation rates-a multicentre, observational survey in critically ill patients. Int J Antimicrob Agents 2010;35:375-81.

[8] Chang EP, Chiang DH, Lin ML, Chen TL, Wang FD, Liu CY. Clinical characteristics and predictors of mortality in patients with Enterobacter aerogenes bacteremia. J Microbiol Immunol Infect 2009;42:329-35.

[9] Anderson B, Nicholas S, Sprague B, Campos J, Short B, Singh N. Molecular and descriptive epidemiology of multidrug-resistant Enterobacteriaceae in hospitalized infants. Infect Control Hosp Epidemiol 2008;29:250-5.

[10] Pagès JM, Amaral L. Mechanisms of drug efflux and strategies to combat them: challenging the efflux pump of Gram-negative bacteria. Biochim Biophys Acta 2009;1794:826-33.

[11] Lomovskaya O, Watkins WJ. Efflux pumps: their role in antibacterial drug discovery. Curr Med Chem 2001;8:1699-711.

[12] Lomovskaya O, Totrov M. Vacuuming the periplasm. J Bacteriol 2005;187:1879-83.

[13] Bailey AM, Paulsen IT, Piddock LJ. RamA confers multidrug resistance in Salmonella enterica via increased expression of $a c r B$, which is inhibited by chlorpromazine. Antimicrob Agents Chemother 2008;52:3604-11.

[14] Klitgaard JK, Skov MN, Kallipolitis BH, Kolmos HJ. Reversal of methicillin resistance in Staphylococcus aureus by thioridazine. J Antimicrob Chemother 2008;62:1215-21. 
[15] Viveiros M, Jesus A, Brito M, Leandro C, Martins M, Ordway D, et al. Inducement and reversal of tetracycline resistance in Escherichia coli K-12 and expression of proton gradient-dependent multidrug efflux pump genes. Antimicrob Agents Chemother 2005;49:3578-82.

[16] Spengler G, Martins A, Rodrigues L, Aagaard L, Martins M, Costa SS, et al. Characterisation of intrinsic efflux activity of Enterococcus faecalis ATCC29212 by a semi-automated ethidium bromide method. In Vivo 2009;23:81-7.

[17] Zharova TV, Vinogradov AD. Energy-linked binding of $P_{i}$ is required for continuous steady-state proton-translocating ATP hydrolysis catalyzed by $F_{0} \cdot F_{1}$ ATP synthase. Biochemistry 2006;45:14552-8.

[18] Su CC, Yu EW. Ligand-transporter interaction in the AcrB multidrug efflux pump determined by fluorescence polarization assay. FEBS Lett 2007;81:4972-6.

[19] Martins A, Spengler G, Rodrigues L, Viveiros M, Ramos J, Martins M, et al. $\mathrm{pH}$ modulation of efflux pump activity of multi-drug resistant Escherichia coli: protection during its passage and eventual colonization of the colon. PLoS One 2009;4:e6656.

[20] Tran QT, Dupont M, Lavigne JP, Chevalier J, Pagès JM, Sotto A, et al. Occurrence of efflux mechanism and cephalosporinase variant in a population of Enterobacter aerogenes and Klebsiella pneumoniae isolates producing extended-spectrum $\beta$-lactamases. Antimicrob Agents Chemother 2009;53:1652-66. 
[21] Ghisalberti D, Mahamoud A, Chevalier J, Baitiche M, Martino M, Pagès $\mathrm{JM}$, et al. Chloroquinolines block antibiotic efflux pumps in antibiotic-resistant Enterobacter aerogenes isolates. Int J Antimicrob Agents 2006;27:565-9.

[22] Espinel-Ingroff A, Fothergill A, Ghannoum M, Manavathu E, OstroskyZeichner L, Pfaller M, et al. Quality control and reference guidelines for CLSI broth microdilution susceptibility method (M 38-A document) for amphotericin B, itraconazole, posaconazole, and voriconazole. J Clin Microbiol 2005;43:5243-6.

[23] Viveiros M, Martins M, Couto I, Rodrigues L, Spengler G, Martins A, et al. New methods for the identification of efflux mediated MDR bacteria, genetic assessment of regulators and efflux pump constituents, characterization of efflux systems and screening for inhibitors of efflux pumps. Curr Drug Targets 2008;9:760-78.

[24] Martins M, Santos B, Martins A, Viveiros M, Couto I, Cruz A, et al. An instrument-free method for the demonstration of efflux pump activity of bacteria. In Vivo 2006;20:657-64.

[25] Viveiros M, Martins A, Paixão L, Rodrigues L, Martins M, Couto I, et al. Demonstration of intrinsic efflux activity of Escherichia coli K-12 AG100 by an automated ethidium bromide method. Int J Antimicrob Agents 2008;31:45862.

[26] Sharples D, Brown JR. Correlation of the base specificity of DNAintercalating ligands with their physico-chemical properties. FEBS Lett 1976;69:37-40. 
[27] Ghisalberti D, Masi M, Pagès JM, Chevalier J. Chloramphenicol and expression of multidrug efflux pump in Enterobacter aerogenes. Biochem Biophys Res Commun 2005;328:1113-8.

[28] Chevalier J, Mahamoud A, Baitiche M, Adam A, Viveiros M, Smarandache A, et al. Quinazoline derivatives are efficient chemosensitizers of antibiotic activity in Enterobacter aerogenes, Klebsiella pneumoniae and Pseudomonas aeruginosa resistant strains. Int J Antimicrob Agents 2010 May 20 [Epub ahead of print].

[29] Viveiros M, Portugal I, Bettencourt R, Victor TC, Jordaan AM, Leandro C, et al. Isoniazid-induced transient high-level resistance in Mycobacterium tuberculosis. Antimicrob Agents Chemother 2002;46:2804-10.

[30] Mulkidjanian AY, Heberle J, Cherepanov DA. Protons @ interfaces: implications for biological energy conversion. Biochim Biophys Acta 2006;1757:913-30.

[31] Kadlec K, Kehrenberg C, Schwarz S. Efflux-mediated resistance to florfenicol and/or chloramphenicol in Bordetella bronchiseptica: identification of a novel chloramphenicol exporter. J Antimicrob Chemother 2007;59:191-6.

[32] Begic S, Worobec EA. Fluoroquinolone resistance of Serratia marcescens: sucrose, salicylate, temperature, and $\mathrm{pH}$ induction of phenotypic resistance. Can J Microbiol 2007;53:1239-45.

[33] Lomovskaya O, Zgurskaya HI, Totrov M, Watkins WJ. Waltzing transporters and 'the dance macabre' between humans and bacteria. Nat Rev Drug Discov 2007;6:56-65. 
[34] Tal N, Schuldiner S. A coordinated network of transporters with overlapping specificities provides a robust survival strategy. Proc Natl Acad Sci U S A 2009;106:9051-6. 
Fig. 1. Effect of pH on the accumulation of ethidium bromide (EB) by strains of Enterobacter aerogenes.

Fig. 2. Effects of $\mathrm{pH}$ and glucose (glu) on the accumulation of ethidium bromide by Enterobacter aerogenes ATCC 13048.

Fig. 3. Effect of glucose (glu) on efflux of ethidium bromide at $\mathrm{pH} 5$ and 8 by (A) Enterobacter aerogenes ATCC 13048 and (B) E. aerogenes CM64 strain.

Fig. 4. Effect of $5 \mathrm{mg} / \mathrm{L}$ carbonyl cyanide $m$-chlorophenylhydrazone (CCCP) on efflux of ethidium bromide at $\mathrm{pH} 5$ and $\mathrm{pH} 8$ by Enterobacter aerogenes: (A1) $E$. aerogenes ATCC 13048, pH 5; (A2) E. aerogenes ATCC 13048, pH 8; (B1) E. aerogenes EA27, pH 5; (B2) E. aerogenes EA27, pH 8; (C1) E. aerogenes CM64, $\mathrm{pH}$ 5; and (C2) E. aerogenes $\mathrm{CM} 64, \mathrm{pH}$ 8. glu, glucose.

Fig. 5. Effect of $40 \mathrm{mg} / \mathrm{L}$ Phe-Arg- $\beta$-naphthylamide $(P A \beta N)$ on efflux of ethidium bromide at $\mathrm{pH} 5$ and $\mathrm{pH} 8$ by Enterobacter aerogenes: (A1) E. aerogenes ATCC 13048, pH 5; (A2) E. aerogenes ATCC 13048, pH 8; (B1) E. aerogenes EA27, $\mathrm{pH}$ 5; (B2) E. aerogenes EA27, $\mathrm{pH}$ 8; (C1) E. aerogenes CM64, $\mathrm{pH}$ 5; and (C2) E. aerogenes CM64, pH 8. glu, glucose. 


\section{Table 1}

Antimicrobial susceptibilities of the Enterobacter aerogenes strains studied $[27,28]$

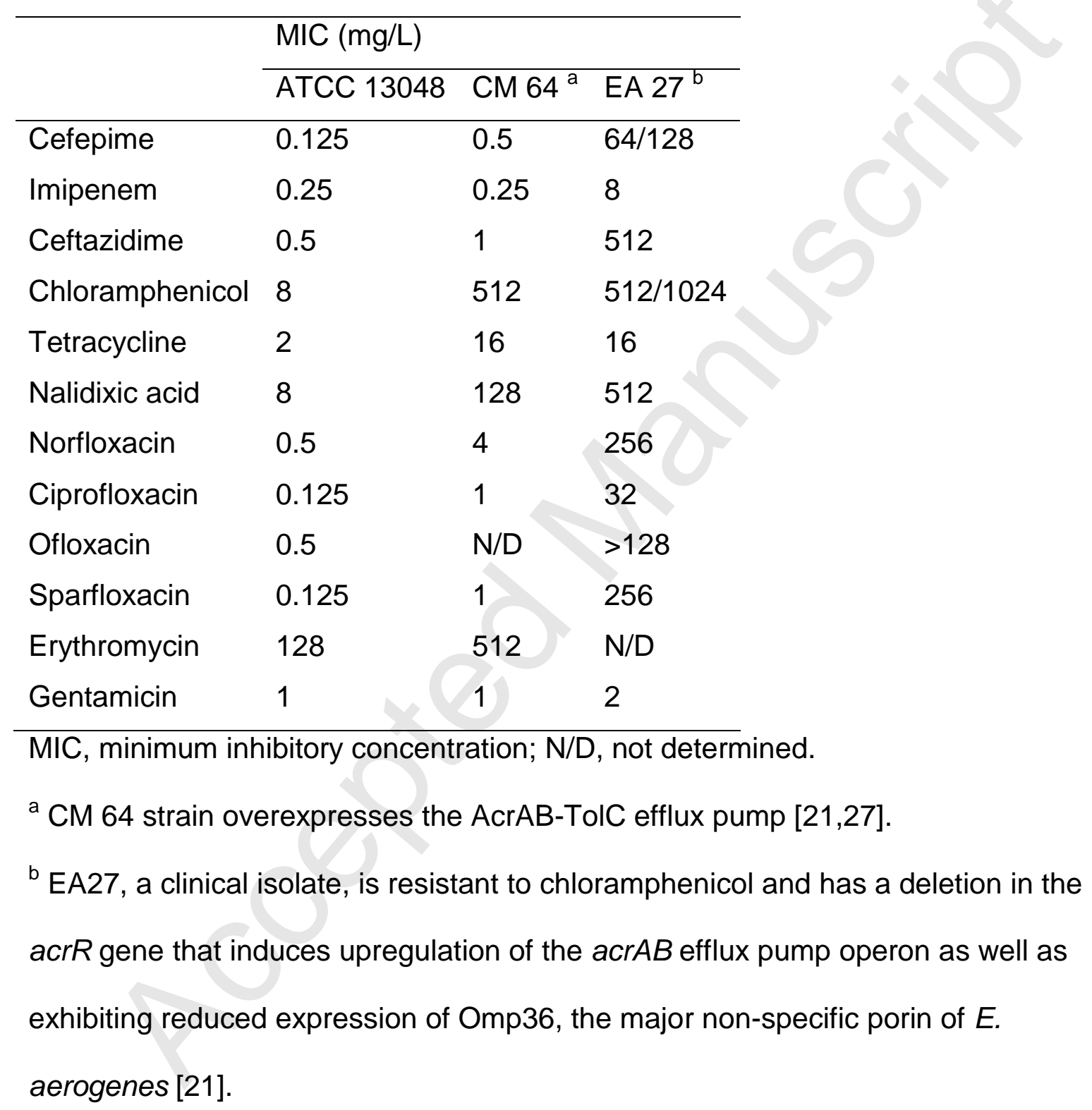




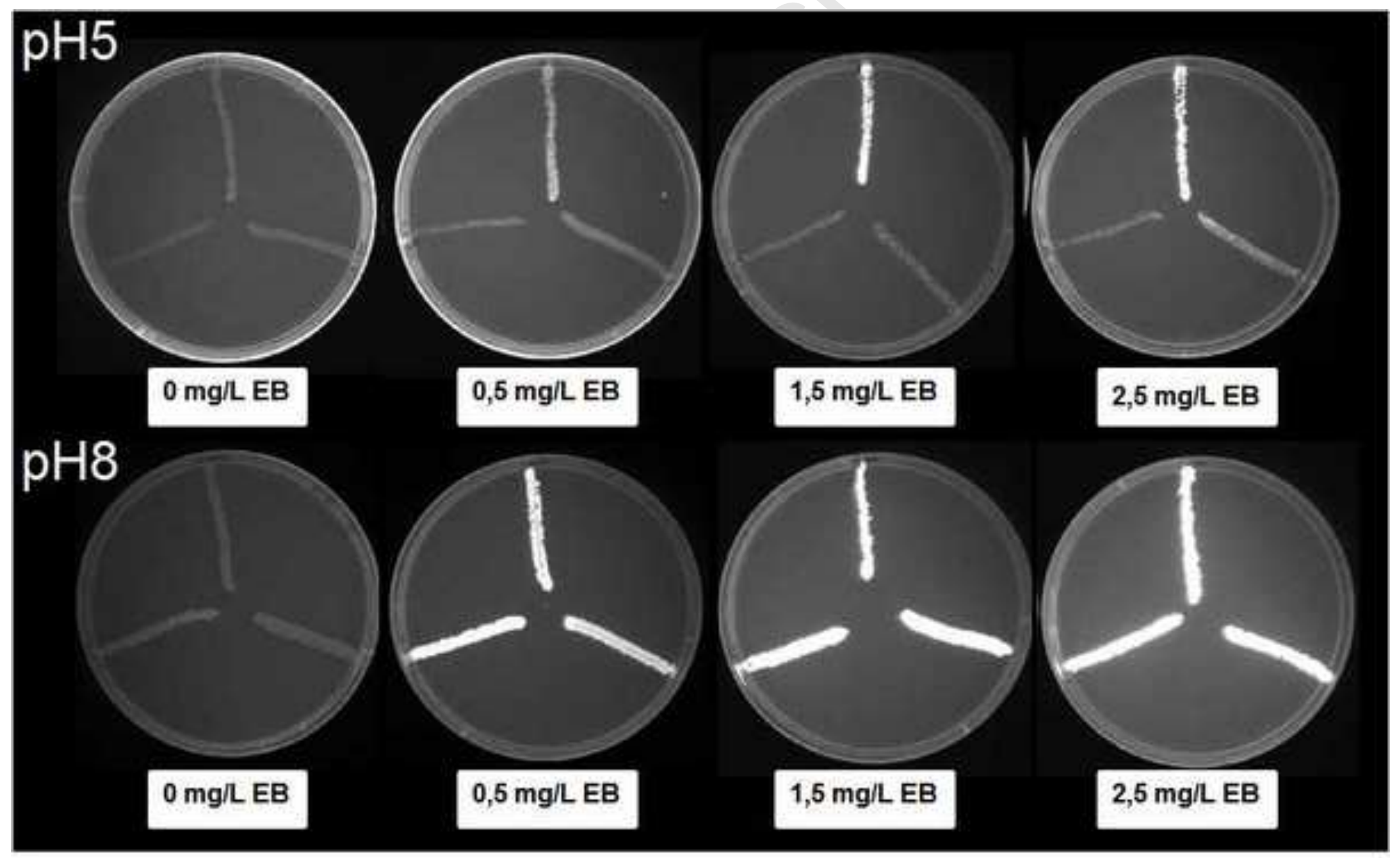

\section{Legend:}

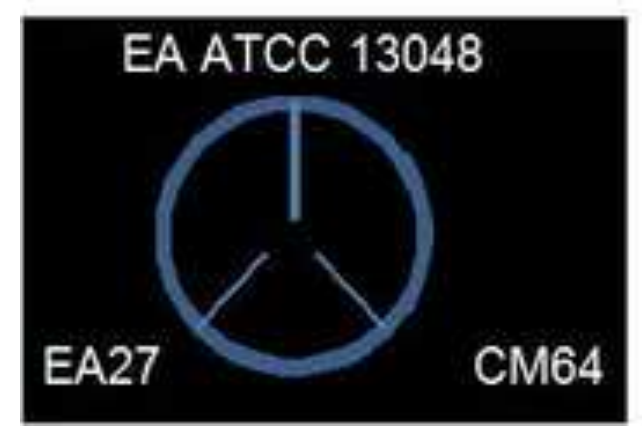




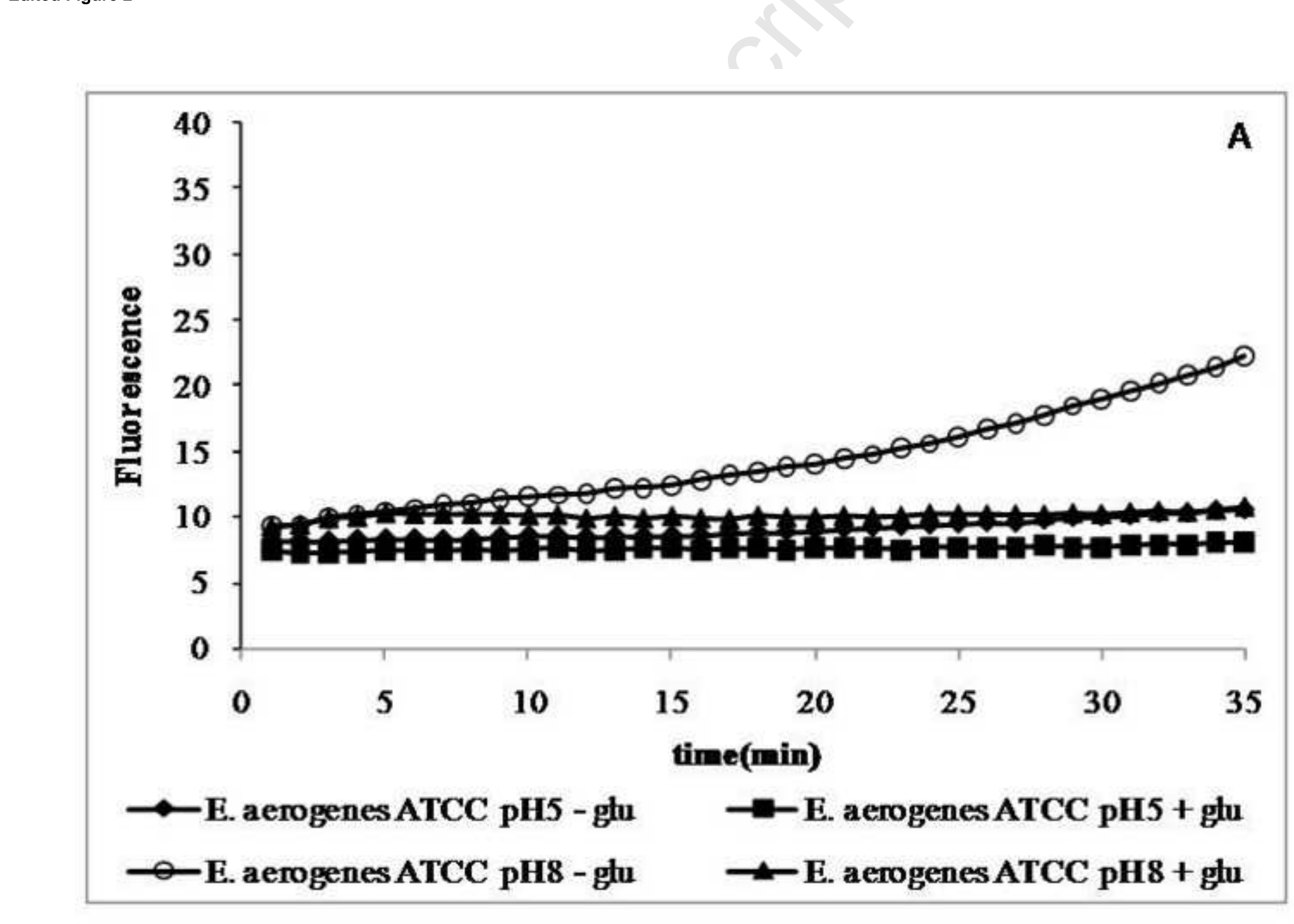

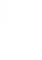

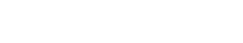

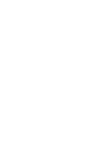

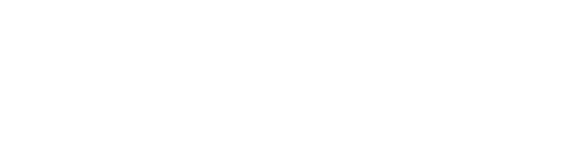

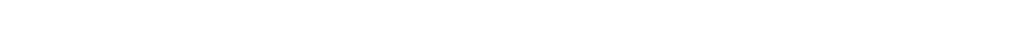



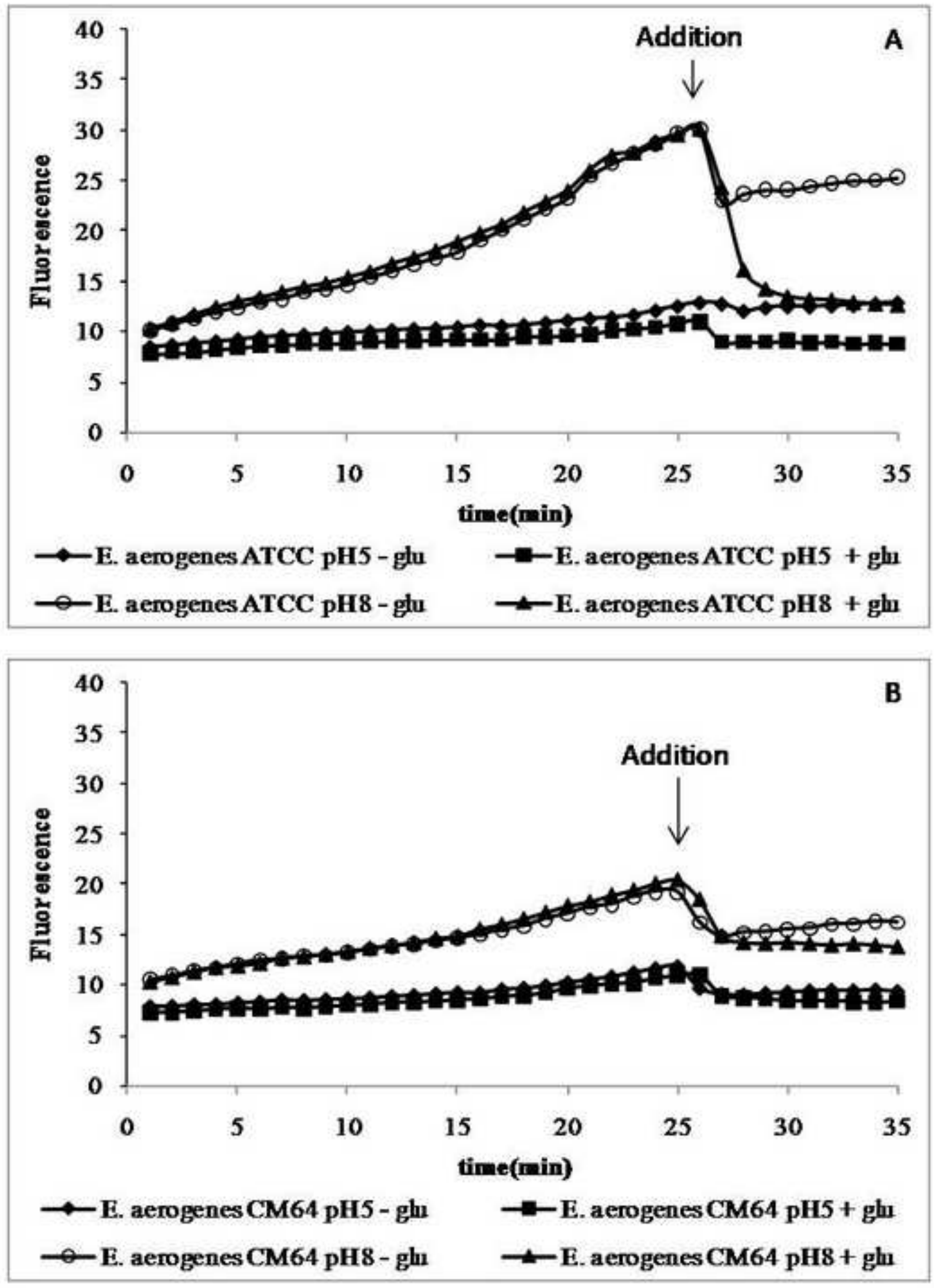


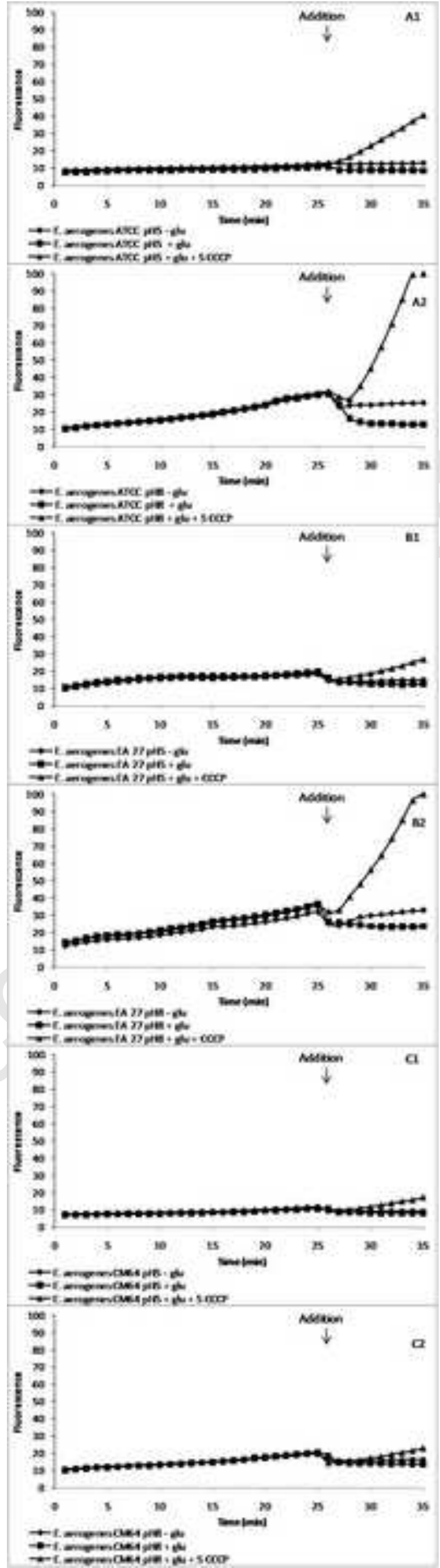




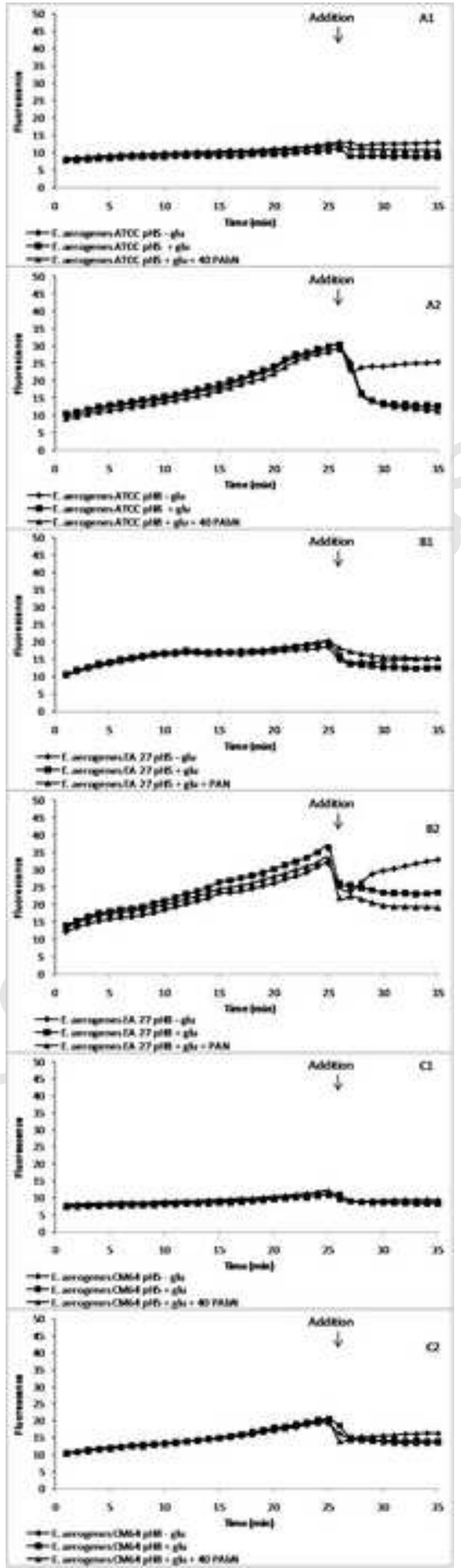

